\title{
Implementing IoT in Underwater communication using Li-Fi
}

\author{
${ }^{1}$ Balaji K S.Shakthivel Murugan
}

\begin{abstract}
Internet of Things (IoT) is attracting more research interest as a result of increased interaction of human with underwater world. IoT technology using Light fidelity (Li-Fi) module plays a vital role in Environmental monitoring, underwater exploration, underwater Disaster management and underwater military Applications. In this paper, we implement IoT in underwater communication using Li-Fi module. However Implementing Li-Fi module in underwater pose grand challenges due to the unique features of underwater channel and acoustic systems. We comprehensively investigate these unique features and finally possible solutions are provided. Simulations are done using MATLAB software to find which color of light emitting diode (LED) is suitable for underwater Communication. It is found that Blue - Cyan-Green Spectral range of wavelength 490nm to $560 \mathrm{~nm}$ is suitable for underwater communication. We obtain low absorption, scattering and attenuation loss in the Blue - CyanGreen Spectral range. An application was developed for the fisherman to identify number and variety of fishes available in particular location.
\end{abstract}

KEYWORDS: IoT, Li-Fi, Underwater, Blue-Cyan-Green Spectral range.

\subsection{INTRODUCTION}

There has been a large demand for high-speed real-time underwater wireless links to load a wide range of underwater applications such as environmental monitoring and pollution control, underwater exploration offshore oilfield exploration, maritime archaeology, ,scientific data collection, port security, and tactical surveillance among others [1].

Generally, Radio waves propagate at a very long distances through conductive sea water only at extra low frequencies $(30-300 \mathrm{~Hz})$, which require a very large antenna and very high transmission power. So radio waves are not suitable for underwater communication [2].

Manuscript Received on July 05, 2019.

${ }^{1}$ Balaji K, Assistant Professor, Department of Electronics and Communication Engineering, Mailam Engineering College Tamilnadu, India; ksbalajiaut@gmail.com

${ }^{2}$ Dr.S.Shakthivel Murugan, Associate Professor, Department of Electronics and Communication Engineering, SSN College of Engineering, Tamilnadu, India, sakthivels@ssn.edu.in
Acoustic communications suffer from a very small available bandwidth less than $100 \mathrm{KHz}$, very low celerity and large latencies due to the low propagation speed [3].

Li-Fi communication provides data rate of more than hundreds of Mbps for short ranges and it is an alternative approach to acoustic communication in underwater [4]

In Li-Fi, light-emitting diode (LED) lamps act as access points (APs), and light is used as a medium to carry information bits. At the receiver, a photo diode is employed to collect photons and convert them into electric current.

At present, $\mathrm{Li}-\mathrm{Fi}$ is a license free communication. The complete architecture of Implementing IoT in Underwater communication using Li-Fi is shown in Fig.1

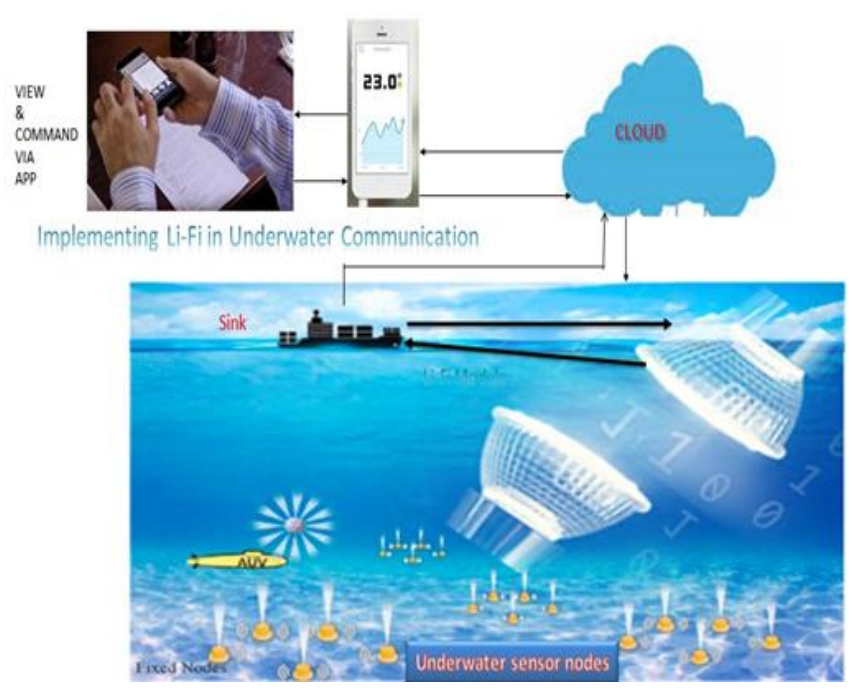

Fig.1. Architecture of Implementing IoT in Underwater communication using Li-Fi

By using li-fi technique, data is transmitted in the form of light. Photo detector absorbs the light and it convert it into electrical signal. The photo detector is placed near the surface of sea. The information is then passed to cloud storage then it is utilized for various Applications. 


\subsection{Optical properties of sea water}

\subsection{The Bio-Optical Model}

Absorption and Scattering are the two major processes that affect light propagation in water depend on wavelength $\lambda$. A propagating light beam is deviated from its initial direction through the scattering process, and a part of its intensity is absorbed and converted into other forms of energy. The scattering and absorption characteristics of a natural water body are called its inherent optical properties (IOPs) and are wavelength dependent.

Applications of these sensors include environmental monitoring and pollution control, underwater exploration offshore oilfield exploration, maritime archaeology, ,scientific data collection, port security, and tactical surveillance. This is type of chlorophyll approach of propagation of light in sea water is called Bio-optical Model.

More dissolved salts constitute about 35 to 45 parts per thousand of the weight sea waters. These salts increase the scattering about $30 \%$ to $40 \%$. They also have an effect on the absorption at visible wavelengths, but they increase absorption for ultraviolet and higher wavelengths: > $800 \mathrm{~nm}$.

Inorganic particles contribute to both scattering and absorption, mainly in turbid waters. On the other hand, organic particles may be in various forms as specified below.

Viruses - in spite of their large numbers, virus particles have a very small impact on both absorption and scattering but can be efficient back scatters at least at blue wavelengths in very clear waters.

Colloids part of the absorption and backscattering attributed to dissolved matter is probably due to colloids.

Bacteria can contribute to absorption, scattering, and backscattering, especially at blue spectral ranges in clear oceanic waters

Organic detritus of various sizes, shapes, and origins, they are considered as the major back scattering in the ocean but are poor scatters and absorbers except at blue wavelengths

Large particles including zooplanktons these particles strongly diffuse the light beam at small scattering angles.

Phytoplankton widely present in most oceanic waters, they play an important role in the optical properties of sea water.

\subsection{Absorption}

In the Bio-optical model, the absorption coefficient is expressed as a sum of all the absorption spectra multiplied by their respective concentrations as [5].

$$
\begin{aligned}
\mathrm{a}(\lambda)= & a_{w}(\lambda)+a_{c}^{0}(\lambda)\left(C / C_{C}^{0}\right)^{0.602}+a_{f}^{0} C_{f} \exp \left(f_{C} \lambda\right) \\
& +a_{h}^{0} C_{h} \exp \left(h_{C} \lambda\right)
\end{aligned}
$$

Where, $\lambda$ is the wavelength and $a_{w}$ is a pure water absorption coefficient $\left(\mathrm{m}^{-1}\right)$. The absorption due to pure sea water with variation of wavelength is shown in Fig.1. In the second term $\mathrm{a}_{\mathrm{c}}^{0}$ denotes is the specific absorption coefficient of chlorophyll $\mathrm{C}_{\mathrm{C}}^{0}=1 \mathrm{mg} / \mathrm{m}^{3}$. The third term denotes $\mathrm{a}_{\mathrm{f}}^{0}=35.959 \mathrm{~m}^{2} / / \mathrm{mg}$ absorption due to fulvic acid present in sea water. The fulvic constant $f_{c}=-0.0189$. Fig. 3 shows the absorption due to fulvic acid with respect to wavelength $(\lambda)$. The fourth terma ${ }_{\mathrm{h}}{ }_{\mathrm{h}}=18.828 \mathrm{~m}^{2} / \mathrm{mg}$ denotes absorption due to humic acid where humic constant $h_{c}=-0.01105$. Fig. 4 shows the absorption due to humic acid with respect to wavelength $(\lambda)$. Some additional absorption also happen due to phytoplankton present under the sea. The absorption due to phytoplankton is shown in Fig.5. Additional relationships between $\mathrm{C}, \mathrm{C}_{\mathrm{f}}$ and $\mathrm{C}_{\mathrm{h}}$ are

$\mathrm{C}_{\mathrm{f}}=1.7408 * \mathrm{C} * \exp \left(0.12327\left(\mathrm{C} / \mathrm{C}_{\mathrm{C}}^{0}\right)\right)$

$\mathrm{C}_{\mathrm{h}}=0.19334 * \mathrm{C} * \exp \left(0.12343\left(\mathrm{C} / \mathrm{C}^{0} \mathrm{C}\right)\right)$

$\mathrm{C}$ is the chlorophyll and its value is given in table 1. [5]

\begin{tabular}{|l|l|}
\hline Water type & Chlorophyll (C) \\
\hline Pure sea & 0.005 \\
\hline Clear ocean & 0.31 \\
\hline Coastal & 0.83 \\
\hline Turbid harbor & 5.9 \\
\hline
\end{tabular}

Table 1. Typical chlorophyll concentration.

Depending on the chlorophyll value the type of water is changed. For example the Pure Sea has a chlorophyll value of 0.005 . For all other water type the chlorophyll value is listed in the table 1 . 
Depending upon the chlorophyll concentration absorption varies. Total absorption with respect to wavelength $(\lambda)$ for Clear Ocean and coastal is shown in Fig.6 and Fig.7 respectively.

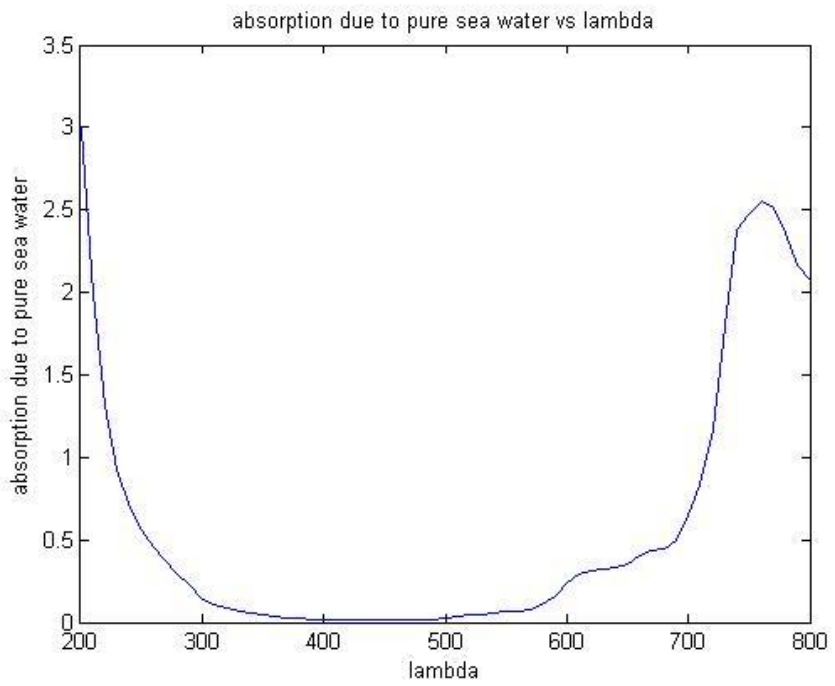

Fig.2. Absorption due to pure sea water vs wavelength

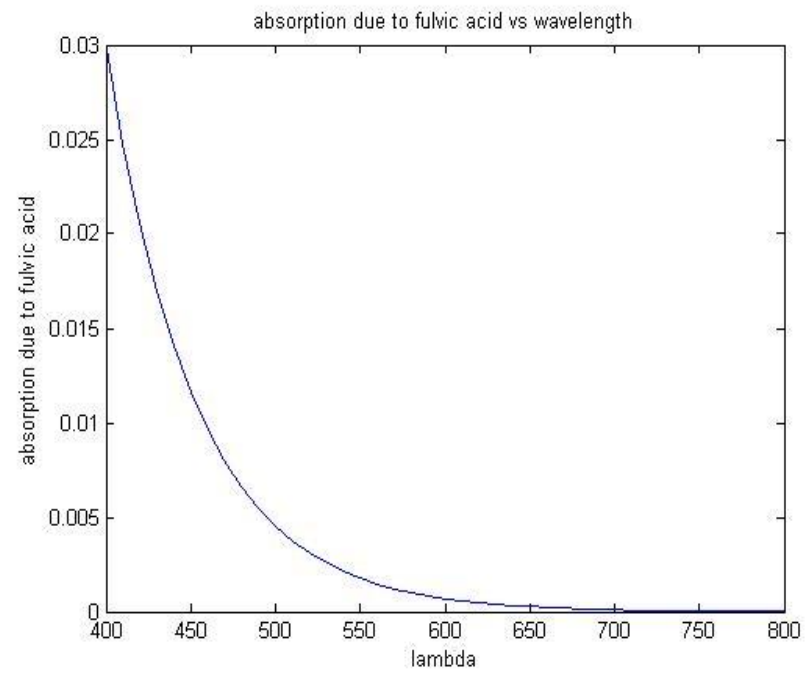

Fig.3. Absorption due to fulvic acid vs wavelength $(\lambda)$

In the Figure 2, it is observed that for the wavelength $(\lambda)$ from $300 \mathrm{~nm}$ to $600 \mathrm{~nm}$ the absorption is very less when compared to all other wavelength. The absorption is higher for the wavelength $200 \mathrm{~nm}$ to $300 \mathrm{~nm}$ and $600 \mathrm{~nm}$ to $800 \mathrm{~nm}$. So from the Figure 2, it is concluded that from $300 \mathrm{~nm}$ to $600 \mathrm{~nm}$ the absorption is very low.

From the Figure 3, it is observed that the absorption due to fulvic acid decreases linearly with increase in the wavelength $(\lambda)$. So from the Figure 3 , it is concluded that for higher wavelength the absorption due to fulvic acid is very low.
Fig.4 Absorption due to humic acid vs wavelength $(\lambda)$

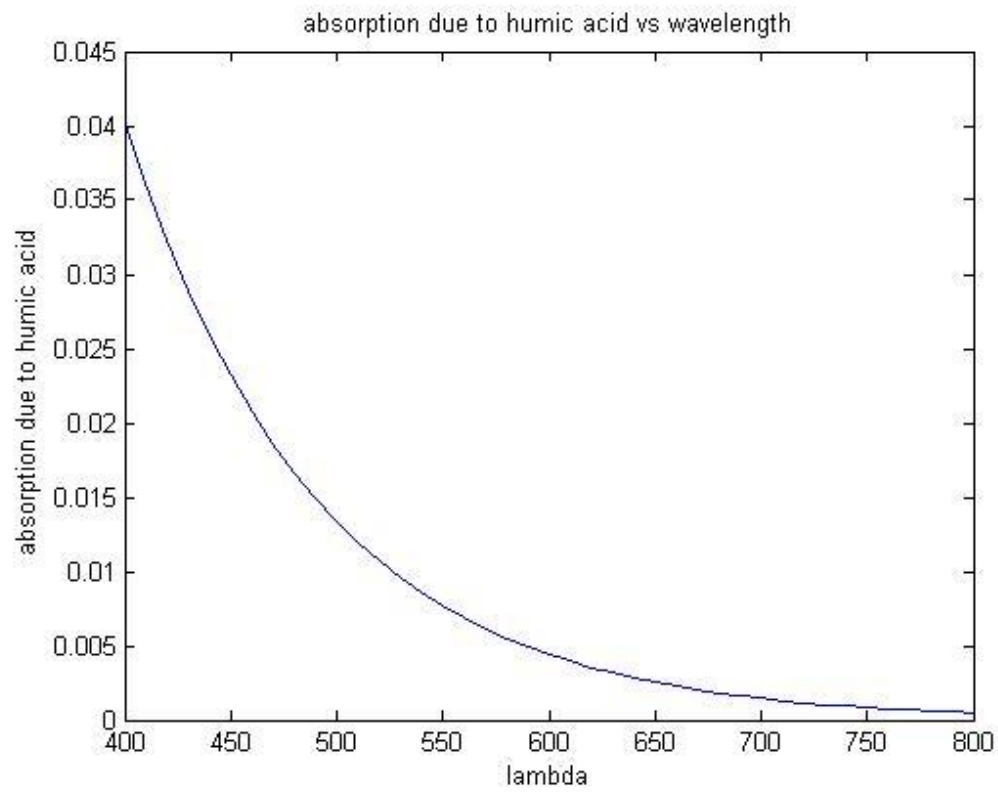

Form the Figure 4, it is observed that the absorption due to humic acid decreases linearly with increase in the wavelength $(\lambda)$. So from the Figure 4, it is concluded that for higher wavelength the absorption due to humic acid is very low.

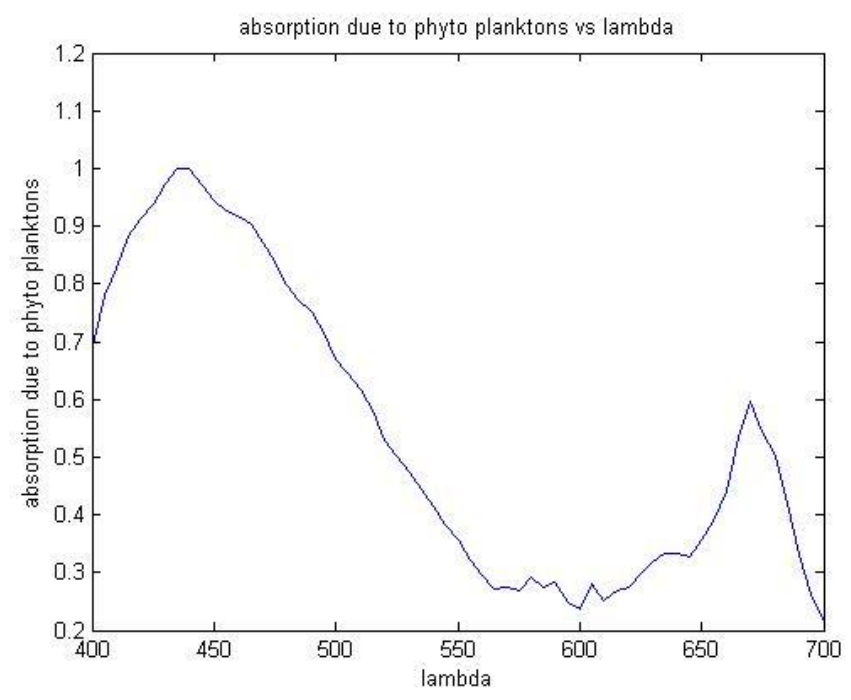

Fig.5. Absorption due to phytoplankton vs wavelength $(\lambda)$

Form the Figure 5, it is observed that the absorption due to phytoplankton is very less in wavelength $(\lambda)$ from $550 \mathrm{~nm}$ to $650 \mathrm{~nm}$. So from the Figure 5, it is concluded that for

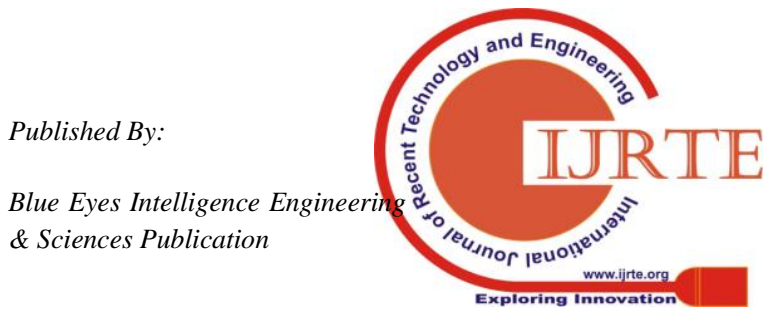


wavelength $(\lambda)$ from $550 \mathrm{~nm}$ to $650 \mathrm{~nm}$ absorption due to phytoplankton is very low

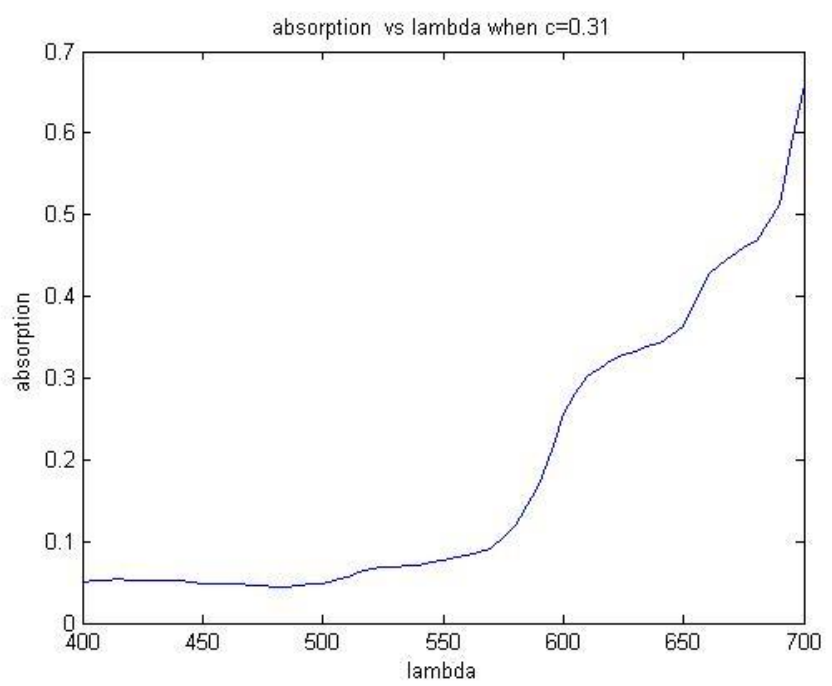

Fig.6. Total absorption vs wavelength $(\lambda)$ for Clear Ocean.

Form the Figure 6, it is observed that for the wavelength ranging from $400 \mathrm{~nm}$ to $550 \mathrm{~nm}$ the total absorption is very less. The total absorption includes absorption due to pure sea, absorption due to fulvic acid, absorption due to humic acid and absorption due to phytoplankton. Figure 6 shows the total absorption for Clear ocean because the chlorophyll value $\mathrm{C}$ is chosen as 0.31 .

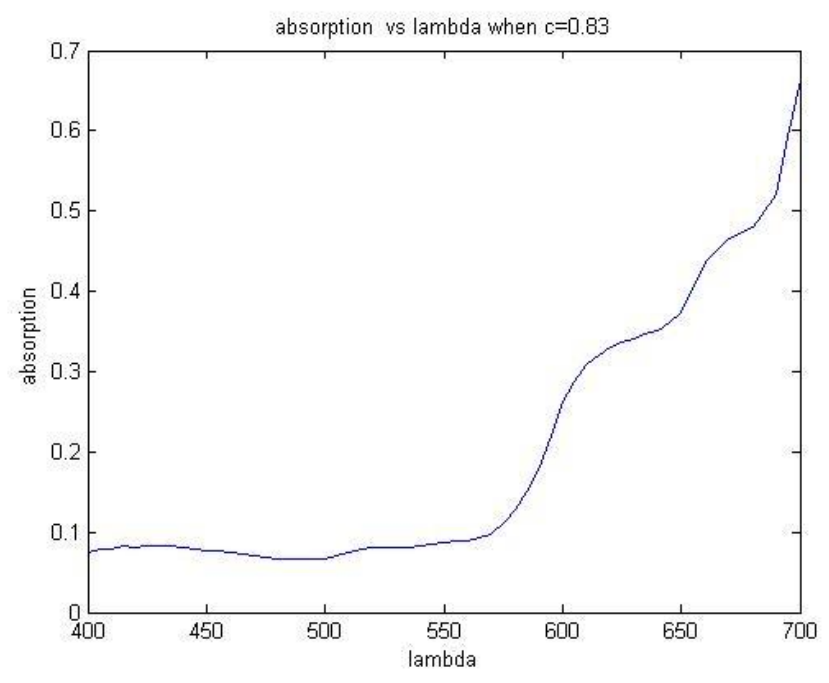

Fig.7.Total absorption vs wavelength $(\lambda)$ for coastal.

From the Figure 7, it is observed that for the wavelength ranging from $400 \mathrm{~nm}$ to $550 \mathrm{~nm}$ the total absorption is very less. The total absorption includes absorption due to pure sea,

absorption due to fulvic acid, absorption due to humic acid and absorption due to phytoplankton. Figure 7 shows the total absorption for Coastal region because the chlorophyll value $\mathrm{C}$ is chosen as 0.83 .

From the Figure 6 and Figure 7, it is clear that the absorption is very less in the wavelength of 400 to $550 \mathrm{~nm}$ region.

\subsection{Scattering}

The scattering coefficient for the bio optical model is a function of wavelength and chlorophyll concentration is given by [7]

$$
b(\lambda)=b_{w}(\lambda)+b_{s}^{0}(\lambda) C_{s}+b_{l}^{0}(\lambda) C_{l}
$$

The Back scattering coefficient for the bio optical model is a function of wavelength and chlorophyll concentration is given by [7]

$b_{b}(\lambda)=0.5 b_{w}(\lambda)+0.039 b_{s}^{0}(\lambda) C_{s}+6.4 \times 10^{-4} b_{l}^{0}(\lambda) C_{l}$

Where,

$b_{w}$ is the pure water scattering coefficient $\left(\mathrm{m}^{-1}\right)$,

$\mathrm{b}_{\mathrm{s}}{ }^{0}$ is the scattering coefficient for small particulate matter $\left(\mathrm{m}^{2} / \mathrm{g}\right)$

$\mathrm{b}_{\mathrm{l}}^{0}$ is the scattering coefficient for large particulate matter $\left(\mathrm{m}^{2} / \mathrm{g}\right)$,

$C_{s}$ is the concentration of small particles $\left(\mathrm{g} / \mathrm{m}^{3}\right)$ and

$C_{l}$ is the concentration of large particles $\left(\mathrm{g} / \mathrm{m}^{3}\right)$.

$C_{s}=0.01739 C_{c} \exp \left(0.11631\left(C_{c} / C^{0}{ }_{C}\right)\right)$

$C_{l}=0.76284 C_{c} \exp \left(0.03092\left(C_{c} / \mathrm{C}^{0}{ }_{\mathrm{C}}\right)\right)$

Small and large particulate matter and its spectral densities are given by

\section{Published By:}

Blue Eyes Intelligence Engineering Sciences Publication 
$b_{w}(\lambda)=0.005826(400 / \lambda)^{4.322}$

(8)

$b_{s}^{0}(\lambda)=1.1513(400 / \lambda)^{1.7}$

(9)

$b_{l}^{0}(\lambda)=0.3411005826(400 / \lambda)^{0.3}$

(10)

Fig. 8 and Fig. 9 shows the scattering effect of Light beam in underwater with respect to wavelength $(\lambda)$ for Clear Ocean and coastal respectively. It is clear that the scattering effect decreases linearly with increase in wavelength. For both the clear ocean and coastal, the scattering effect decreases with increase in wavelength.

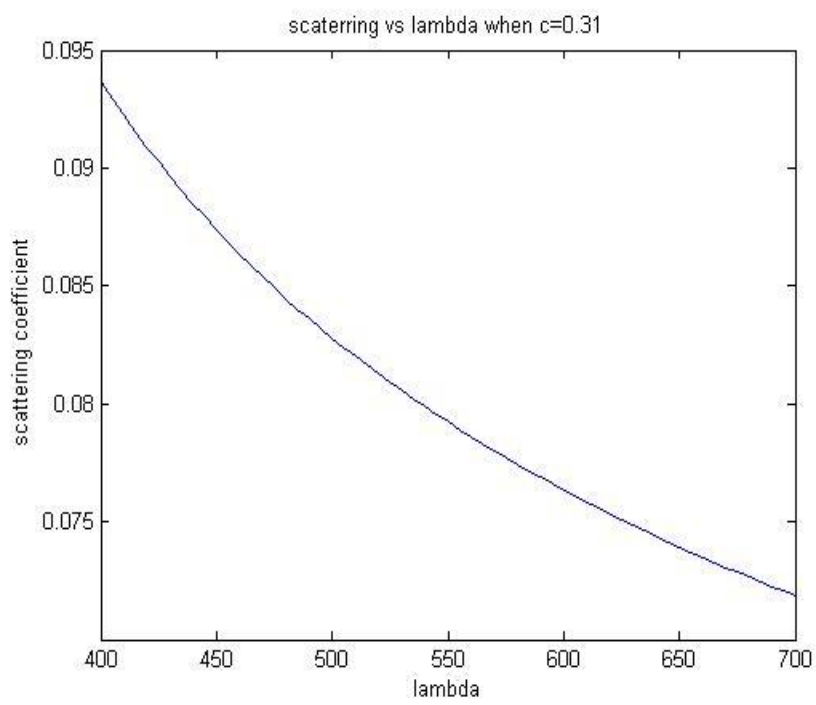

Fig.8. Scattering vs wavelength $(\lambda)$ for Clear Ocean

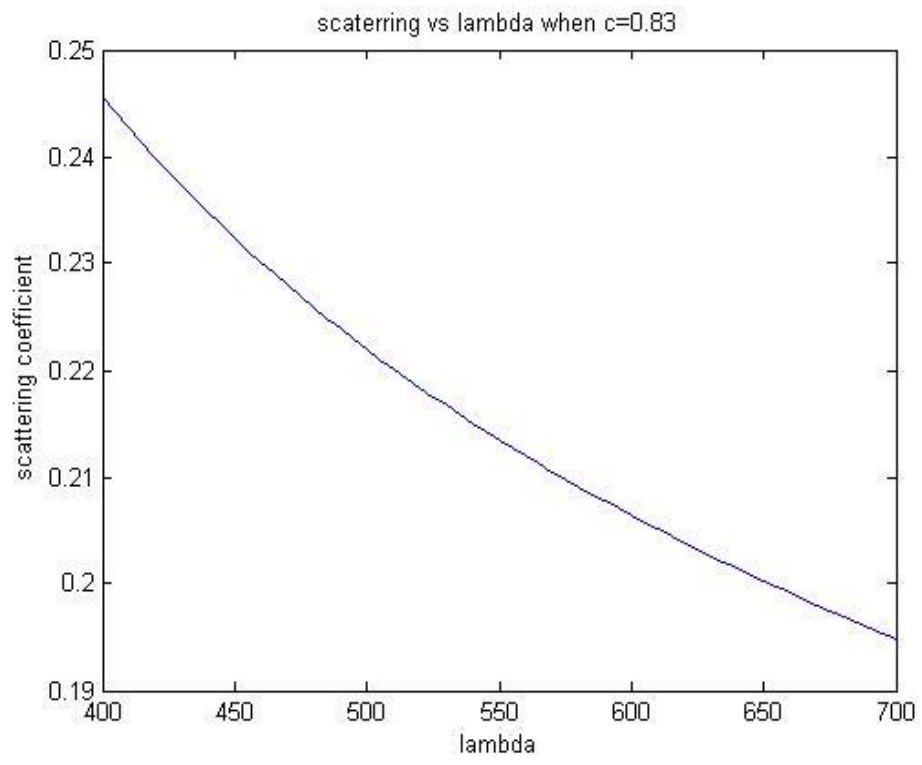

Fig.9. Scattering vs wavelength $(\lambda)$ for Coastal.

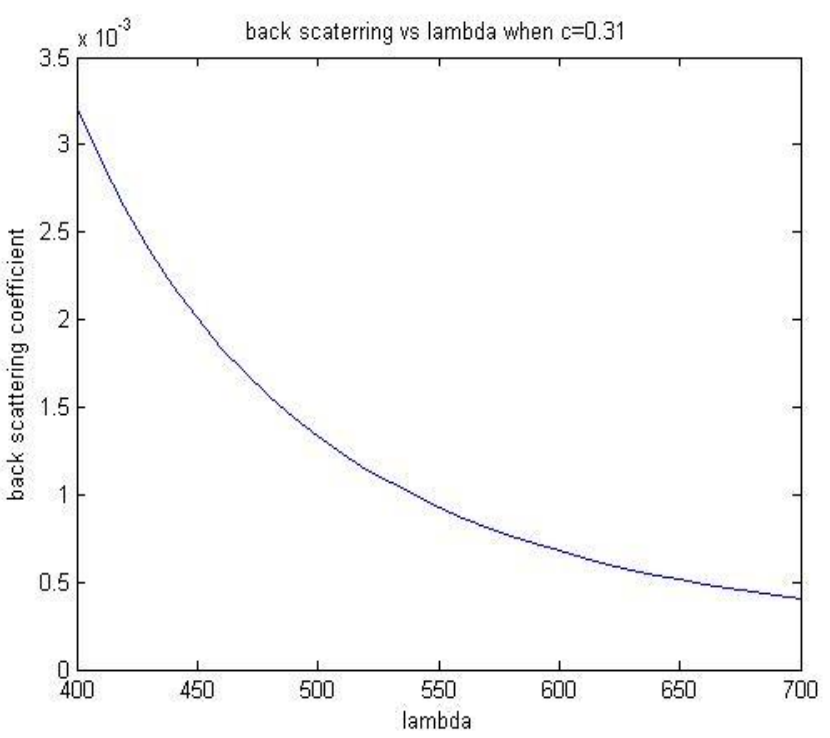

Fig.10. Back scattering vs wavelength $(\lambda)$ for Clear Ocean

'ublished By:

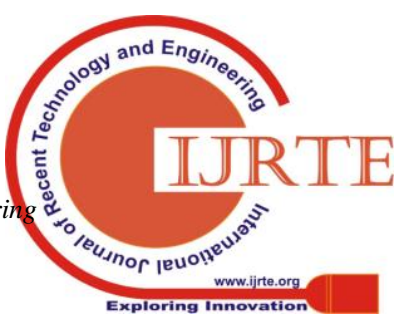




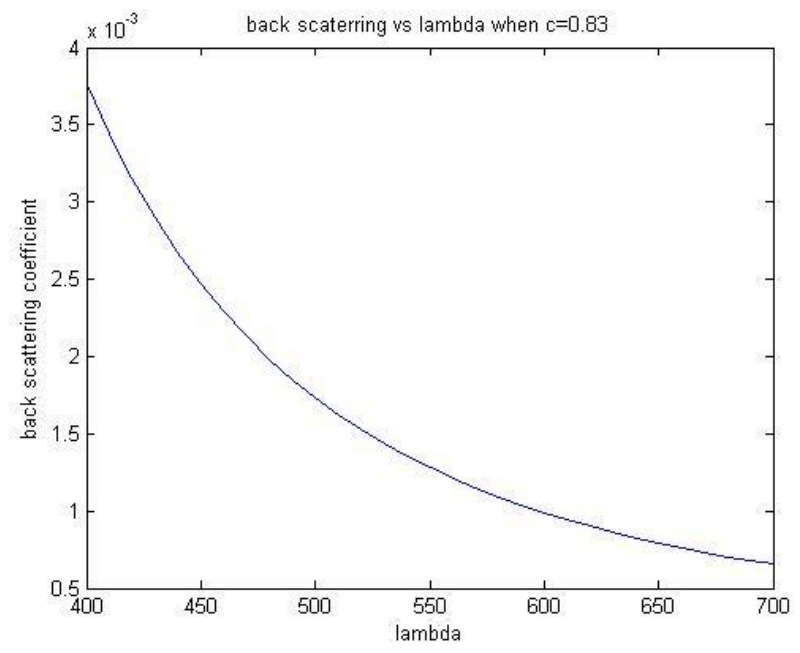

Fig.11. Back scattering vs wavelength $(\lambda)$ for Coastal.

Figure 10 and Figure 11 shows the back scattering effect. The back scattering effect decreases with increase in wavelength. Although, the back scattering shows negligible effect on the process, it may also the consider for getting effective efficiency.

\section{Attenuation}

Finally, adding total absorption $a(\lambda)$ and scattering $b(\lambda)$ gives the spectral beam attenuation coefficient $c(\lambda)$, also called the extinction coefficient

$c(\lambda)=a(\lambda)+b(\lambda)$

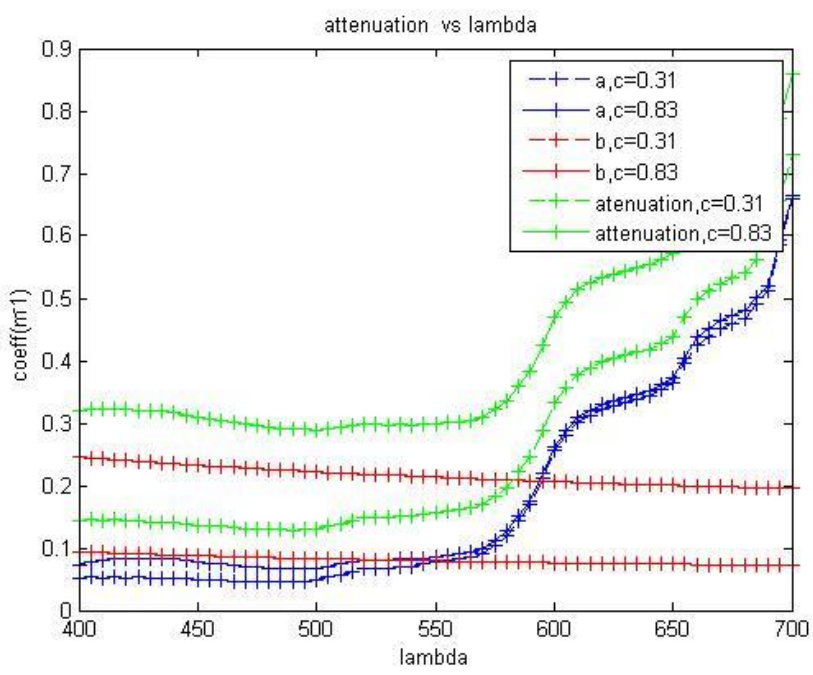

Fig.12. Total attenuation vs wavelength $(\lambda)$ for clear ocean and coastal.
Fig.12 shows the attenuation coefficient varies with wavelength $(\lambda)$ for both Clear Ocean and coastal area. It is clear that the total attenuation is the sum of total absorption and total scattering. From the figure 12, it is clear that for the wavelength between $400 \mathrm{~nm}$ to $560 \mathrm{~nm}$ the attenuation is very low.

The colour range with respect to wavelength $(\lambda)$ is shown in table 2. From the table it is clear that violet-blue-cyan-green light is suitable for effective transmission. The violet light is not in the market. So blue-Cyan-Green spectral range is chosen as transmission light.

The violet light is not in the market. So blue-Cyan-Green spectral range is chosen as transmission light.

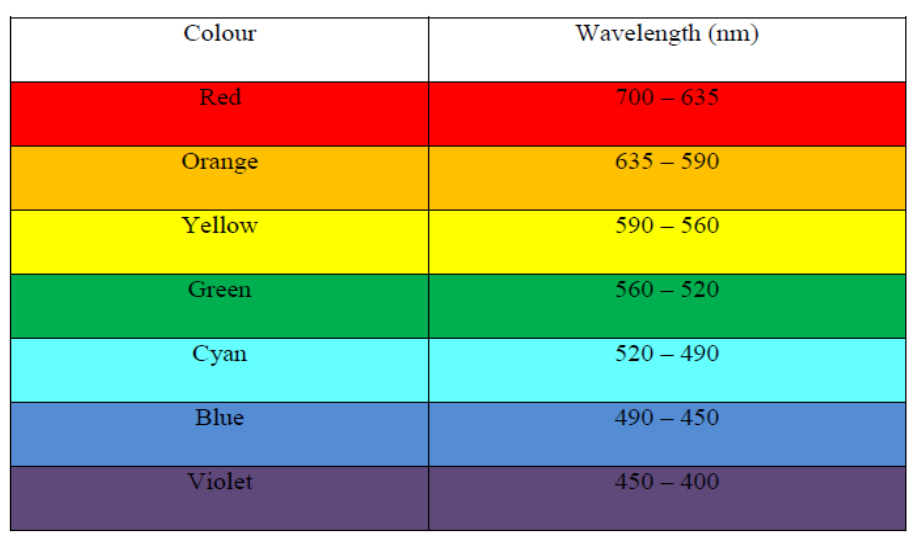

Table 2. Colour vs Wavelength

\section{Conclusion}

Currently, the Acoustic waves are used for the purpose of underwater communication. Now we are implementing $\mathrm{Li}-\mathrm{Fi}$ as an IoT for underwater communication. When the photodetector receives the signal, it sends to sink. Later the results can be exported to cloud. We have received the details via mobile application.

\section{Acknowledgement}

Our research work is carried out in Underwater Acoustic Research Lab, Department of Electronics and Communication Engineering, SSN College of Engineering, Chennai, Tamilnadu. 


\section{References}

[1]. Automatic Billing System using Li-Fi Module Zubin Thomas, Nikil Kumar and D. Jyothi Preshiya International Conference on Communication and Signal Processing, April 6-8, 2016, India

[2]. P. A. Haigh, F. Bausi, T. Kanesan, S. T. Le, S. Rajbhandari, Z. Ghassem- looy,I. Papakonstantinou, et al. A $10 \mathrm{Mb} / \mathrm{s}$ visible light communication system using a low bandwidth polymer light-emitting diode. In 2014 9th International Symposium on Communication Systems, Networks Digital Signal Processing (CSNDSP), pages 999- 1004, July 2014.

[3]. P. A. Haigh, F. Bausi, T. Kanesan, S. T. Le, S.Rajbhandari, Z. Ghassemlooy,I. Papakonstantinou, et al. A $20-\mathrm{Mb} / \mathrm{s}$ VLC link with a polymer LED and a multilayer perceptron equalizer. IEEE Photon. Technol. Lett., 26(19):1975- 1978, 2014.

[4]. P. A. Haigh, F. Bausi, Z. Ghassemlooy, I. Papakonstantinou, H. Le Minh, C. Flechon, and F. Cacialli. Next generation visible light communications: $10 \mathrm{Mb} / \mathrm{s}$ with polymer light-emitting diodes. In Optical Fiber Communications Conference and Exhibition (OFC), 2014,pages1- 3, March 2014.

[5]. C. Gabriel, M.A. Khalighi, S. Bourennane, P. Léon, and V. Rigaud, Monte Carlobased channel characterization for underwater optical communication systems, IEEE/OSA J. Opt. Commun. Networking, vol. 5, no. 1, pp. 1- 12, 2013.

[6]. V.I. Haltrin and G.W. Kattawar, Self-consistent solutions to the equation of transfer with elastic and inelastic scattering in oceanic optics: I. Model, Appl. Opt., vol. 32, no. 27, pp. 5356- 5367, 1993.

[7]. V. I. Haltrin, "Chlorophyll-based model of seawater optical properties," Appl. Opt., vol. 38, no. 33, pp. 6826_6832, 1999.

[8]. C. Gabriel, M.A. Khalighi, S. Bourennane, P. Léon, and V. Rigaud, Investigation of suitable modulation techniques for underwater wireless optical communications, International Workshop on Optical Wireless communications (IWOW), pp. 1-3, October 2012, Pisa, Italy.

[9]. Z. Ghassemlooy, A. Hayes, N. Seed, and E. Kaluarachchi, Digital pulse interval modulation for optical communications, IEEE Commun. Mag., vol. 36, no. 12, pp. 95-99, 1998

\section{Bibliography}

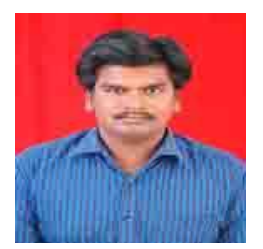

Mr.Balaji K Working as an Assistant Professor in the department of Electronics and Communication at Mailam Engineering College, Mailam, Tamilnadu. He had completed B.E. Electronics and Communication at Anna university, Tiruchirappalli and M.E. Control and Instrumentation at College of Engineering, Guindy, Chennai. Currently he is Pursuing his doctorate under Dr. S. Sakthivel Murugan who working as an Associate Professor in the Department of ECE at SSN College of Engineering, Chennai, India. His areas of research are underwater acoustic signal processing and underwater sensor network.

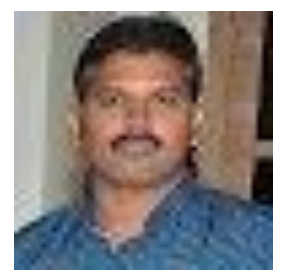

Dr. S. Sakthivel Murugan is working as an Associate Professor in the Department of ECE at SSN College of Engineering, Chennai, India. He has more than 15 years of experience in both academic and research. His areas of research are underwater acoustic signal processing, underwater sensor network, and underground communication. He has established an Underwater/Underground Research Laboratory at SSNCE. To his credit, he has received young researcher award by 2015 . He is the investigator for various projects funded by NIOT, TNSCST, DST and SSNCE. 